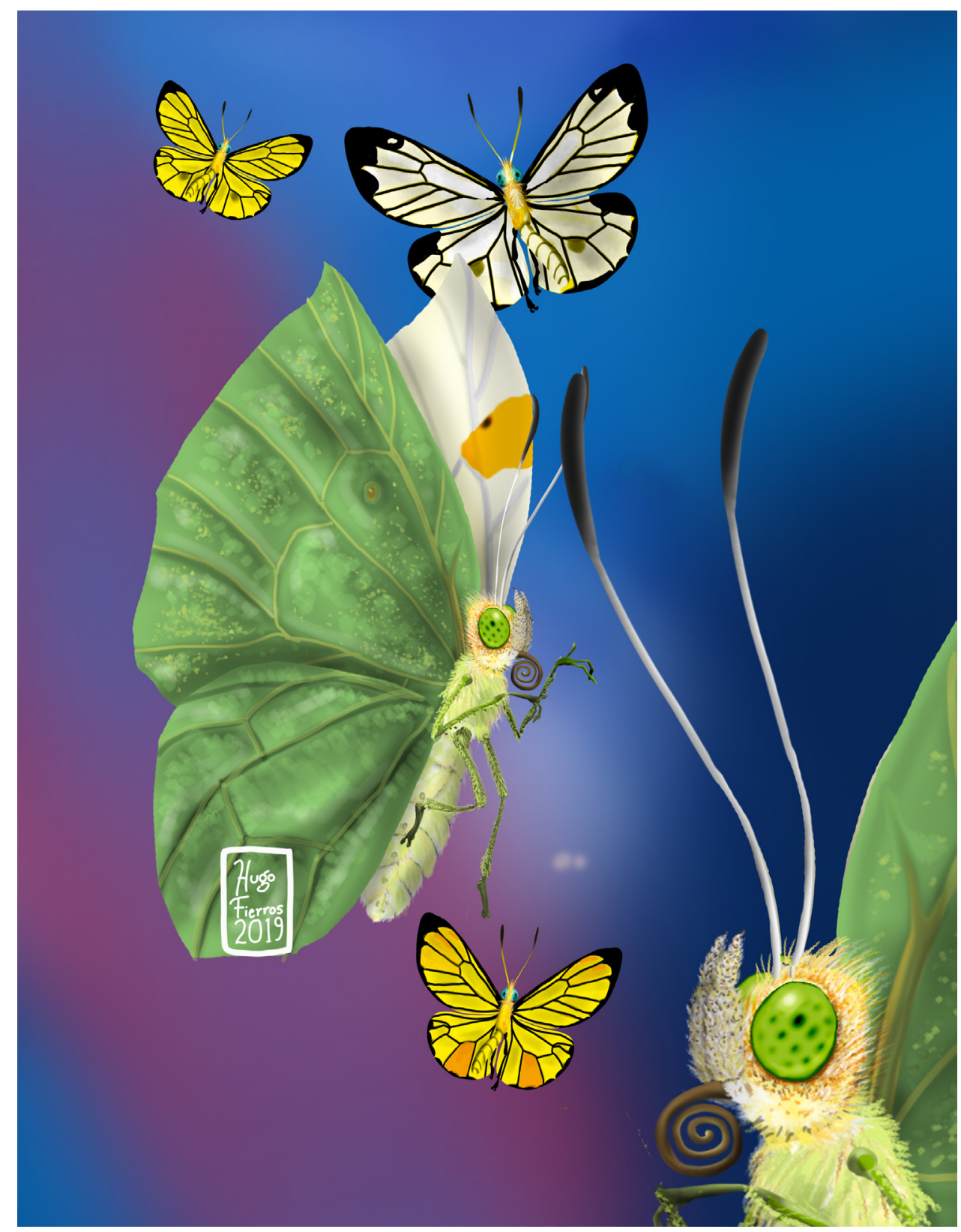

Dugesiana, Año 26, No. 2, julio 2019-diciembre 2019 (segundo semestre de 2019), es una publicación semestral, editada por la Universidad de Guadalajara, a través del Centro de Estudios en Zoología, por el Centro Universitario de Ciencias Biológicas y Agropecuarias. Camino Ramón Padilla Sánchez \# 2100, Nextipac, Zapopan, Jalisco, Tel. 37771150 ext. 33218, http://148.202.248.171/dugesiana/index.php/DUG/index, glenusmx@gmail.com. Editor responsable: José Luis Navarrete Heredia. Reserva de Derechos al Uso Exclusivo 04-2009-062310115100203, ISSN: 2007-9133, otorgados por el Instituto Nacional del Derecho de Autor. Responsable de la última actualización de este número: José Luis Navarrete Heredia, Editor y Ana Laura González-Hernández, Asistente Editorial. Fecha de la última modificación 25 de julio 2019, con un tiraje de un ejemplar.

Las opiniones expresadas por los autores no necesariamente reflejan la postura del editor de la publicación.

Queda estrictamente prohibida la reproducción total o parcial de los contenidos e imágenes de la publicación sin previa autorización de la Universidad de Guadalajara. 


\title{
Remembranza
}

\section{Recuerdos del porvenir}

\author{
Memories for the future
}

Jorge E. Llorente Bousquets

Profesor Emérito, Museo de Zoología (entomología), Facultad de Ciencias, UNAM, enantia@prodigy.net.mx

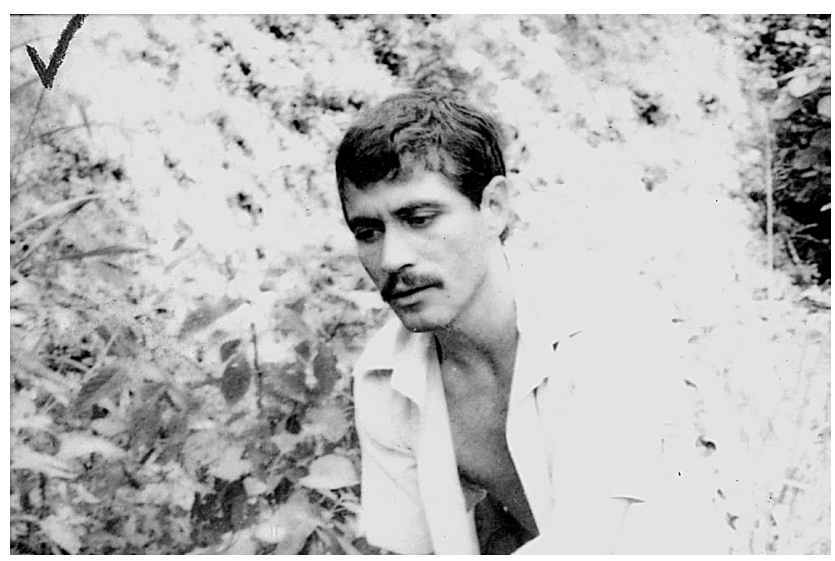

De mis años de juventud (1976).

Desde muy pequeño me cautivaron los insectos, en particular las mariposas; ya hacia los seis y siete años había comenzado mi primera colección, con especímenes de la Ciudad de México. La influencia de mi hermano Ricardo fue muy importante, así como el interés de amigos de mi edad y entorno, quienes competíamos por poseer los ejemplares más raros, grandes y difíciles de atrapar. No obstante, carecíamos de habilidades y conocimientos técnicos para preservarlos. Solo más tarde mi madre me proveyó de un librito sobre mariposas de Norteamérica, además de que constantemente recibía sus consejos y sugerencias. Sin embargo, este fue uno de los "hobbies" a los que me dedicaba los fines de semana y durante vacaciones, pues el deporte colectivo (basquetbol, volibol, béisbol y fútbol) también fue una actividad que reclamaba mi participación con amigos. Desde luego, y también por influencia familiar y más tarde vecinal, el ajedrez se convirtió en uno de mis juegos favoritos, casi un vicio intelectual. Yo vivía y recolectaba insectos en el sur de la ciudad, en los alrededores de Coyoacán y Coapa, pero hacía excursiones a distintos lugares suburbanos, en las vecindades semi-rurales de la megalópolis como Atizapán, Los Dínamos en la Magdalena Contreras, Tlalpan, Xochimilco, La Sierrita de Guadalupe al norte del aeropuerto, y también incursiones en multitud de baldíos, terrenos abandonados, parques y jardines; así también en Chapultepec como en los antiguos viveros de

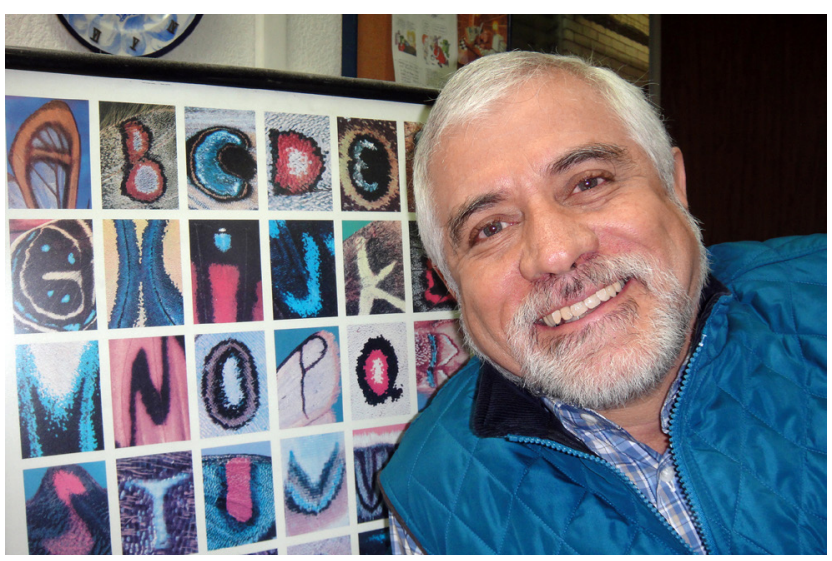

En fechas recientes (2011).

Coyoacán. En aquella época compraba mis aditamentos en la farmacia París y en variados locales de la calle de Correo Mayor, en el centro de la ciudad.

Entre la afición al ajedrez, las mariposas y el basquetbol, acabé decidiendo estudiar biología. No obstante, al final del bachillerato, un grupo de profesores había influido mucho en mi para estudiar matemáticas. Aunque ya era tarde, pues tomé el área terminal de químico-biológicas y no quería perder un año más, pues había concluido la preparatoria a los 17 años, repitiendo el segundo año de preparatoria debido a mis inclinaciones ajedrecísticas. No obstante, en 1971 la larga huelga del proceso sindical naciente en la UNAM, me obligó a esperar varios meses dedicados al ajedrez y a recolectas que ahora hacía en los estados de México, Hidalgo y Morelos. Yo solo o con algún amigo, tomábamos algún camión guajolotero los viernes por la noche y regresábamos los domingos por la tarde con extraordinarios especímenes nunca vistos por la gran ciudad. Más adelante quise cambiarme a la carrera de Matemáticas, pero la insolvencia económica fue un impedimento.

Mi primer trabajo sobre mariposas fue sobre la proporción o razón sexual de Leucanella leucane (Saturniidae), que se constituyó en una plaga de los 'truenos' (Ligustrum japonicum), árboles de ornato introducidos en muchos sitios de la ciudad, en especial en las aceras y 
jardines de varias colonias adyacentes al centro del entonces Distrito Federal. Con ayuda de Katya Luna ese trabajo lo publicamos mi amigo Jorge Soberón y yo en la naciente revista de la Sociedad Mexicana de Lepidopterología, que con sorna siempre nos referimos a ella como la Sociedad de Lepidopterología a la mexicana, que prácticamente desapareció a dos décadas de su fundación.

Tal vez estudié Biología por la falta de guía vocacional, pues mis intereses también radicaban en otras áreas que requieren mayor especialización en las certezas, como las matemáticas. A veces siento como una especie de frustración que he sustituido con lecturas sobre la historia de las matemáticas. La historia de la ciencia, bajo la influencia del inolvidable profesor Alfredo Barrera, pronto se constituyó en otro tema de mi interés. Mostré estas inclinaciones en la redacción de mi primer libro La Búsqueda del Método Natural, publicado por el Fondo de Cultura Económica, en su serie La Ciencia desde México, que coordinaba la física Alejandra Jaidar y más tarde María del Carmen Farías. Este libro lo hice bajo el apoyo y estímulo de Juan Luis Cifuentes, exdirector de la Facultad de Ciencias, UNAM.

Desde mediados de los 1970's, la pequeña pero notable biblioteca de mi consejero y tutor (Alfredo Barrera) influyó en mis intereses en la historia; en particular una obra de Nelson Papavero de São Paulo, Brasil, que trata sobre la historia de la Dipterología en América. Tuve la fortuna de haber caído en la órbita de un profesor de la UNAM, al que se consideró uno de los más cultos en humanidades y en ciencia, quien me apoyó al igual que Anita Hoffmann en mis aventuras de política estudiantil. Me refiero en especial al grupo académico de estudiantes que llamamos Centro de Investigación sobre Artrópodos (CISA) del que fui precursor y líder. Alfredo Barrera había sido el director del Museo de Historia Natural de la Ciudad de México y en aquel entonces era uno de los entomólogos mexicanos más prestigiosos y afamados, con el mayor conocimiento en sistemática, biogeografía e historia de la entomología. Aunque él era especialista en sifonápteros, tenía también interés en mariposas. Además, nos dictó dos cursos en entomología, dos más en sistemática y otros dos en biogeografía, que influyeron decisivamente en mis tareas académicas posteriores, en especial durante mi posgrado.

Recuerdo muy bien que, cuando le pedí que asesorara al grupo estudiantil que encabezaba, él me dijo que sus intereses estaban ya en la etnobotánica, pero nuestra presión lo obligó incluso a ir al campo con nosotros y a seguir un proyecto sobre la comunidad de artrópodos asociados con las bromeliáceas (Tillandsia spp.) del derrame lávico del Chichinautzin, Morelos, por la curva de la pera en la carretera Ciudad de México-Cuernavaca. Al poco tiempo me subrayó y reconvino sobre lo que debía hacer como biólogo o biogeógrafo que quería ser, estas fueron más o menos sus palabras: "Si Usted quiere tomar como modelo para sus estudios biogeográficos a los sifonápteros o los coleópteros ectoparásitos (tal vez forontes), lo puedo ayudar. Sin embargo, le recomiendo tomar a un grupo por el que sienta predilección y tenga experiencia de campo". Así fue y elegí a las mariposas; ya estaba convencido que debía dejar para mejor ocasión a las matemáticas y que para la biogeografía tenía que seguir los consejos de mi tutor académico: "Si Usted quiere conseguir una buena formación como biogeógrafo debe orientarse fuertemente a la Sistemática, en especial a la especiación y filogenia, pero bajo un modelo de estudio (taxón y región) que lo puede acompañar a lo largo de su carrera y profesión". Así lo hice.

Desde aquel tiempo, entonces, la sistemática teórica y la biogeografía junto con las mariposas piéridas, se convirtieron en mi brújula, para orientarme en este mapa cultural y científico sobre la biología en México y la lepidopterología mundial.

Finalmente recuerdo otra de las enseñanzas de Alfredo Barrera, que fue su extraordinario orden para hablar de las especies de insectos respecto a la sucesión jerárquica de caracteres que los diagnostican. Siempre refería a la frase del médico y evolucionista español Faustino Cordón, que decía más o menos así: "los seres vivos son un conjunto de especies que se dejan clasificar jerárquicamente siguiendo la sucesión de atributos que los caracterizan". Él aclaraba que esa jerarquía era producto de la evolución, que se estudiaba a través de la filogenia, que comprendía la genealogía, la polaridad o dirección evolutiva, las relaciones y las afinidades espaciales (geográficas), así como las sucesivas radiaciones de caracteres y sus grupos que acontecían concomitantemente con procesos y eventos geológicos o paleoclimáticos.

Con esta dotación intelectual, tempranamente me tuve que dedicar al grupo de mi interés sin sus consejos y compañía, pues una situación terminal lo obligó a dejar nuestros empeños. Hacia 1981 acudí al primer simposio de lepidopterología neotropical, celebrado en Maracay, Venezuela, al que me presentaba recién graduado y con dos proyectos en avance: 1. El estudio de las Dismorphiinae de México (Lepidoptera, Pieridae), y 2. La seriación en alturas de los anillos miméticos en un bosque mesófilo de montaña, así como la composición de complejos y especies en el ámbito de límites septentrionales de la fauna de mariposas de afinidad neotropical. Ahí conocí a una generación de colegas lepidopterólogos, con los que he venido relacionándome desde hace casi cuatro décadas; haciendo amistades, cursos, viajes y artículos conjuntos.

Entre la fundación del Museo de Zoología, en el que me habían apoyado Anita Hoffmann, Alfredo Barrera y Juan Luis Cifuentes, así como una vasta cantidad de jóvenes estudiantes talentosos y dedicados y la sucesión de visitas a colecciones en Estados Unidos, América Latina y Europa, además del inicio de la colección, con base en una sucesión de estudios faunísticos comencé a dedicarme a la sistemática y biogeografía en nuevos horizontes académicos. Desde principios de los 1980's dicté numerosos cursos y seminarios acerca de mimetismo en mariposas, biogeografía contemporánea (biogeografía cladística y de la vicarianza, biogeografía de Mesoamérica) y sistemática 
(museos y colecciones, sistemática filogenética). Esta serie de cursos se interrumpió cuando tuve que suspender mi proyecto de sabático en Europa, para incorporarme a la Comisión Nacional para el Conocimiento y Uso de Biodiversidad, bajo invitación de José Sarukhán y Jorge Soberón. En ella me desempeñé como director de análisis y prioridades, concomitante a mi nuevo desafío: producir textos modernos en sistemática y biogeografía de nuevo cuño para los estudiantes en la UNAM, que más tarde llegaron a estudiantes sudamericanos.

Por esas fechas y de manera simultánea, comencé a tener una enorme influencia de mi amigo y colega brasileño Nelson Papavero, quien accedió a visitarme en México y dictar un curso sobre taxonomía y biogeografía a través de la teoría de conjuntos, tema sobre el que recientemente había publicado un libro con el lógico y matemático Jair Minoro Abe, también de São Paulo.

Papavero pronto me convenció para que publicáramos una serie de libros y a celebrar un conjunto de cursos de actualización y especializados en historia, filosofía, técnicas y métodos en biología comparada, a través de los pilares fundamentales de esta área biológica: la sistemática y la biogeografía. Me adherí a su programa y de 1992 hasta el año 2004; todos esos años nos visitamos para proseguir en un área de la que él era líder en América Latina. Publicamos varias decenas de libros en México y Brasil, con apoyo de la UNAM, el Fondo de Cultura Económica y FAPESP, una agencia del Estado de São Paulo en Brasil que financia infraestructura de equipo, proyectos científicos, visitas académicas y publicaciones de obras científicas. Él me interesó aún más en la historia y filosofía de la biología, centrado en la biología comparada y a través de los cuatro conjuntos de cursos en México y los otros cuatro a nivel internacional, celebrados dos veces en la Ciudad de México
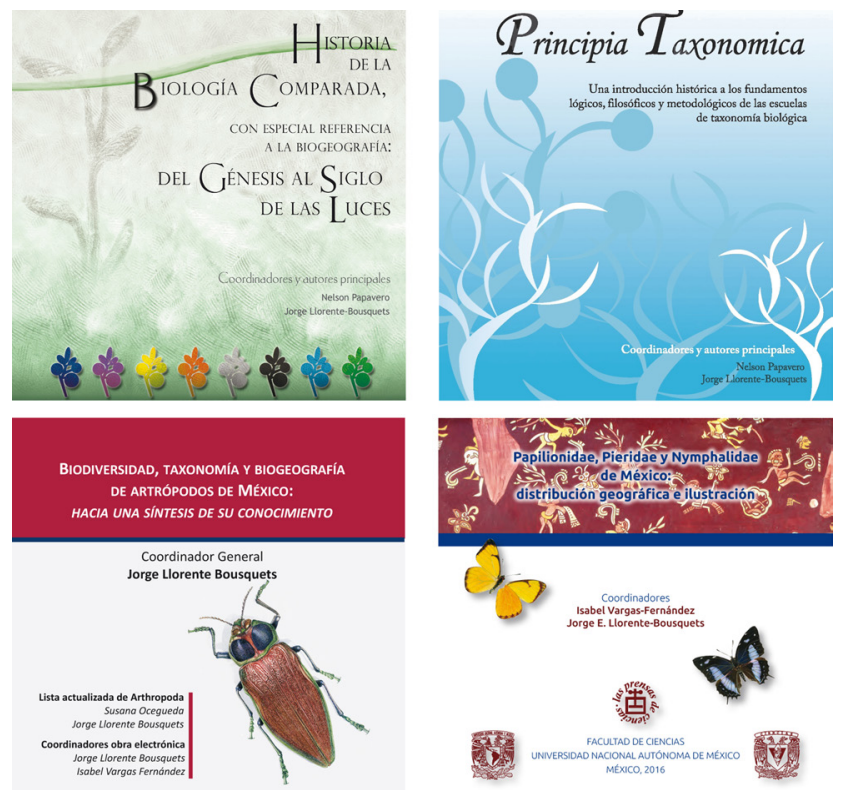

Ediciones electrónicas del autor y sus coautores de cuatro series de libros en Biodiversidad de artrópodos y Mariposas de México, y Fundamentos de Sistemática y Biogeografía.
(UNAM e IPN), Monterrey (UANL), y el Colegio de la Frontera Sur-Chetumal, así como en Quito, Guatemala, Río de Janeiro y La Plata, con apoyo de universidades de esos países y CYTED-RIBES.

Tales cursos consistían en una dupla fundamental: llevar a los mejores profesores de México y Latinoamérica a una selección de estudiantes bien calificados, que se dedicaban por unas semanas o meses con los instrumentos y obras de manera gratuita. Se trataba de mejorar la formación de los nuevos taxónomos en áreas histórico-filosóficas, teórico-conceptuales y técnico-algorítmicas de la biología contemporánea. Los estudiantes egresados llevaban conocimientos y decenas de libros a sus instituciones, bajo la influencia de profesores expertos en una docena de temas. Los profesores provenían de España, Portugal, Brasil, México, Venezuela, Argentina, Perú, Ecuador y Colombia, principalmente. Todo ello propició la generación de una "biblioteca" en los fundamentos de sistemática y biogeografía que después se ha proseguido en la UNAM con el ímpetu nuevamente infligido por el liderazgo de Juan José Morrone, David Espinosa, Alfredo Bueno, Armando Luis y Tania Escalante.

Por todo este desarrollo que inicié con la complicidad de Nelson Papavero, considero que estimulamos un cambio en la sistemática y la biogeografía. En aquel tiempo tales disciplinas se veían rancias y parcialmente obsoletas. Más allá de la entomología, considero que imprimimos un interés renovado en la biología comparada, heredando una nueva generación de taxónomos críticos y propositivos, así como de textos y visiones en la biología teórica e histórica.

Desde las primeras visitas a colecciones y museos que realicé, nunca olvidé los consejos de Barrera: "Un taxónomo tiene que acopiar, consultar y asimilar todo lo que se haya generado sobre el taxón y/o tema taxonómico de su interés bajo estudio; sean publicaciones, producciones gráficas y datos de ejemplares en colecciones, especialmente de colecciones formadas por celebridades y el material tipo que fundamentó las propuestas de especialistas y taxónomos previos". Solo así puede comprender mejor sus descubrimientos y los de otros, así como comparar mejor sus resultados para elaborar mejores conclusiones

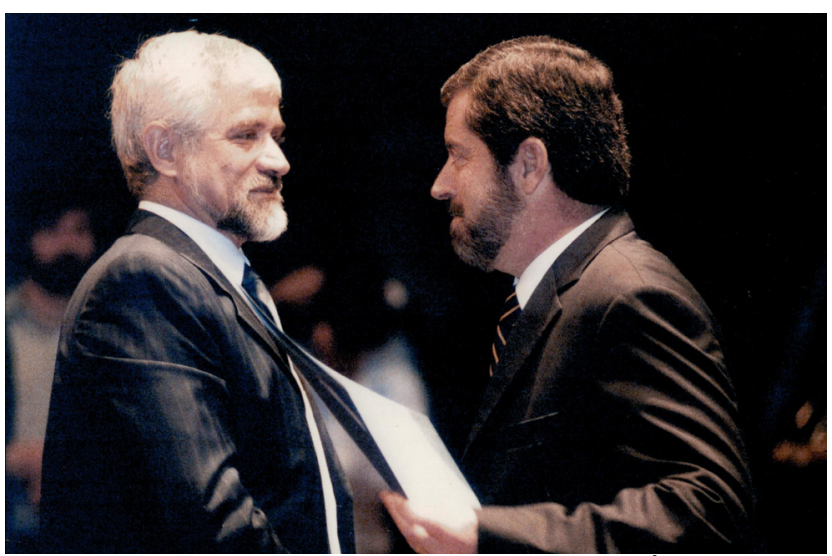

Recibiendo el Premio Universidad Nacional en el Área de Ciencias Biológicas, UNAM, 2003. 


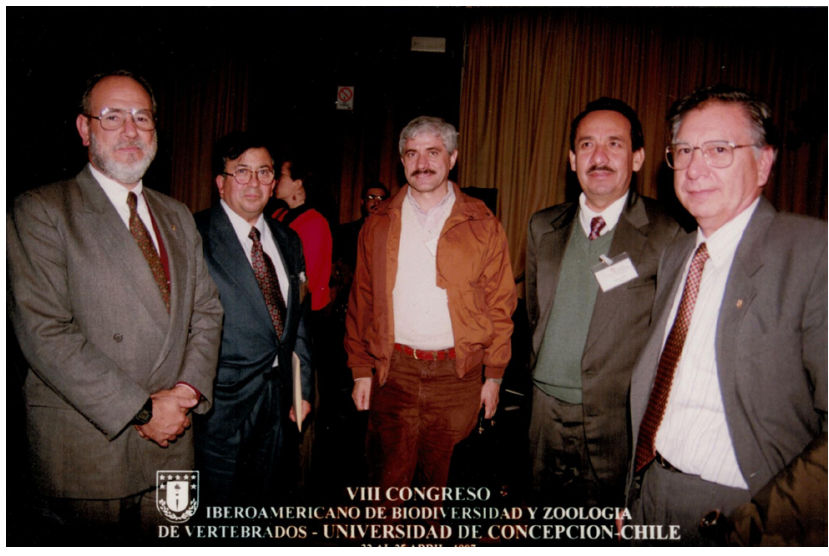

Concepción, Chile en 1995.

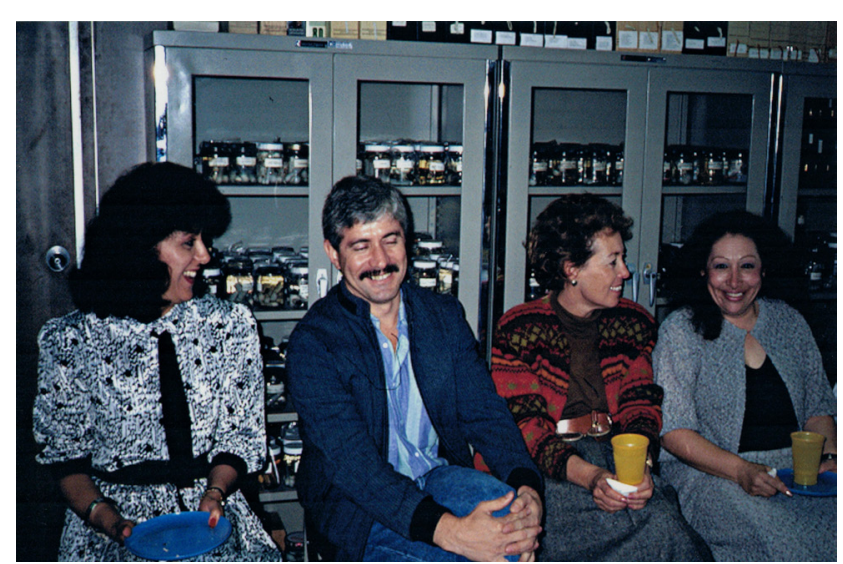

Una fiesta de fin de año (1989) en la UNAM.

de la lepidopterología.

Algo muy satisfactorio para mí es ver a mis estudiantes efectuando trabajo de primera línea y con altos estándares, sea en el campo, en las colecciones, en temas especializados de frontera, en la elaboración de evidencia visual de corte original, en la producción de explicaciones novedosas y propuestas robustamente sustentadas. Ver un grupo de personas productivas e independientes en diversas líneas, taxones, regiones geográficas e instituciones, tal vez es uno de mis mayores legados. La producción de conocimiento original de alto nivel no solo es un motivo de orgullo para las personas, sino también para las instituciones y las naciones.

El haber alcanzado casi 450 publicaciones a la fecha, representadas por un número importante de libros, capítulos y artículos -casi siempre celebrados con amigospara mí es una enorme satisfacción; siendo franco, esta diarrea verbal comenzó cuando para mí lograr escribir bien un párrafo en los 1970's, era toda una proeza. La lectura de temas diversos, así como la reflexión y la práctica de la redacción, alimentado con una fuerte dosis de trabajo de campo y gabinete, de crítica constante y de disciplina académica es una fuerte posología para el mejoramiento del espíritu humano, sobre todo cuando priva la estimación y reconocimiento de los estudiantes y en especial cuando hay una significativa comprensión de los colegas y del entorno familiar.

No soy un experto en toda la investigación entomológica en México, ni sé, ni cuento con suficientes elementos para comentar la situación actual y perspectivas de ésta en nuestro país. Sólo podría ofrecer mi humilde opinión y mis, lamentablemente, deseos y proclividades; aunque estaría dispuesto a conversarlo y debatirlo.

Finalmente deseo agradecer la larga compañía que he tenido durante esta aventura científica e intelectual en la entomología. De entre muchos amigos mecenas, colegas y estudiantes, la lista sería más larga de lo que he escrito hasta ahora, pero so riesgo de olvidar a alguno de los más importantes y con muchas disculpas anticipadas, sin ningún orden agradezco a: Jimena Castro Gerardino, Armando Luis Martínez, Isabel Vargas Fernández, Sandra Nieves 
Uribe, Carmen Pozo de la Tijera, Jorge Soberón Mainero, Blanca Claudia Hernández Mejía, Juan Carlos Morales, Ricardo Ayala Barajas, Hugo Ponce Ulloa, José Palacios Vargas, Tila María Pérez Laclette, Enrique González Soriano, Miguel Ángel Morón Ríos, Fernando Fernández Castiblanco, Pedro Reyes, Gonzalo Halffter, Alma Solis, Robert K. Robbins, Andrew D. Warren, Adriana Briscoe,

Recibido: 11 de julio 2019

Aceptado: 18 de julio 2019

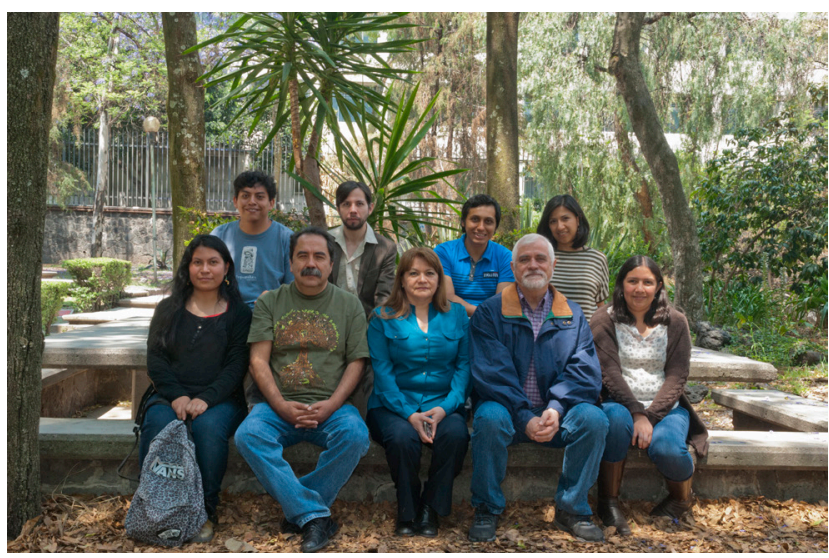

Grupo de Lepidoptera del Museo de Zoología, Facultad de Ciencias, UNAM en 2018.
Arthur M. Shapiro, Nelson Papavero, Olaf Mielke, Mirna Casagrande, Juan José Morrone, Jorge V. Crisci, Gareth Nelson, Frederick Rindge, Lee D. Miller, Marisol Trujano, Arturo Arellano, Eduardo González, Jacqueline Miller, Dale Jenkins, Carlos Cordero, Roxana Acosta, Ángel Viloria, Gerardo Lamas, Giovanni Onore, Gonzalo Andrade, María Eugenia Díaz Batres y muchos otros más que mi cándido Alzheimer me conduce a olvidar.

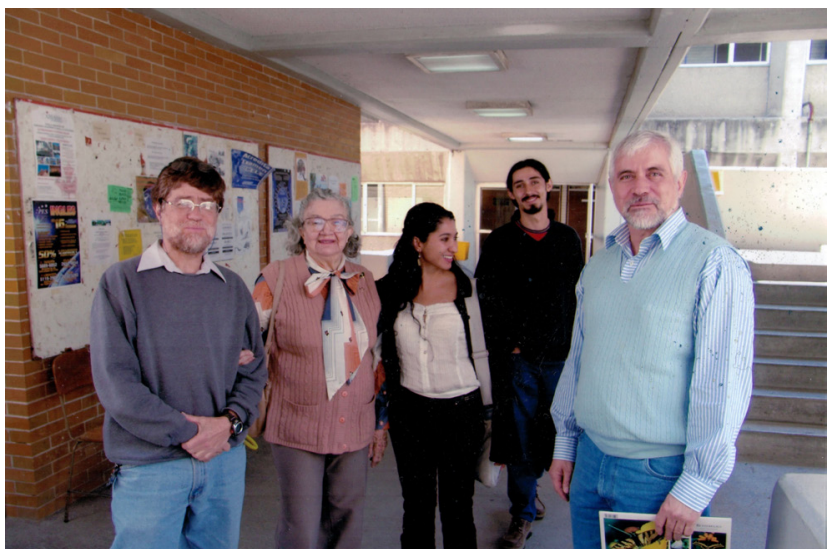

Dra. Anita Hoffmann y exalumnos en el año 2006, Facultad de Ciencias, UNAM. 